\title{
Revocatoria del mandato y democracia: análisis de las experiencias recientes en Lima y Bogotá
}

\section{The Recall Referenda and Democracy: An Analysis of Recent Experiences in Lima and Bogota}

Yanina Welp y Julieta Rey

Recepción: 29 de agosto de 2014 Aceptación: 8 de septiembre de 2014

\section{Resumen}

A comienzos de los noventa, los países andinos han transformado sus marcos normativos, abandonando el modelo estrictamente representativo para incluir diversas instituciones de participación ciudadana. Colombia y Perú fueron pioneros en la incorporación de mecanismos de participación ciudadana a su constitución. El presente articulo se centra en las experiencias recientes de revocatoria del mandato en Lima y Bogotá, a fin de analizar la medida en que éstas expresan o no el buen funcionamiento de la democracia, atendiendo al diseńo institucional del referendum revocatorio, el rol de los actores involucrados y los resultados de estos procesos.

Palabras clave: revocatoria del mandato, mecanismos de democracia directa, representación, democracia, legitimidad.

\begin{abstract}
From the early nineties, the Andean countries have undergone transformations regarding their legal frameworks, from a purely representative model to include diverse institutions for citizen participation. Colombia and Peru were leaders in the incorporation of citizen participation mechanisms to their constitution. This article focuses on the recent experiences of recall referenda of Lima and Bogota, in order to analyze up to which point do these express a good performance of democracy or not, attending to the institutional design of the recall referenda, the roll of the main actors involves and the results of both processes.
\end{abstract}

Keywords: recall referenda, mechanism of direct democracy, representation, democracy, legitimacy. 


\section{Introducción}

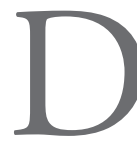

esde principios de los noventa, los países andinos han vivido una profunda transformación de sus marcos normativos, que han abandonado el modelo estrictamente representativo para incluir diversas instituciones de participación ciudadana. Colombia y Perú fueron los primeros en impulsar este cambio por vía de la asamblea constituyente, en 1991 y 1993 respectivamente.

Actualmente, la activación de revocatorias de mandato - un mecanismo de democracia directa (MDD) convocado por la ciudadanía para consultar sobre la interrupción del mandato de una autoridad electacontra los alcaldes de las ciudades capitales, Susana Villarán en Lima (2013) y Gustavo Petro en Bogotá (2014), volvió a otorgar un lugar pionero a estos dos países. Pero pese a las semejanzas, las diferencias entre ambos casos son considerables, empezando por la consulta misma, que tuvo lugar en Lima mientras en Bogotá fue cancelada por la destitución previa del alcalde por la Procuraduría Nacional. El objetivo de este trabajo es analizar a profundidad los resultados de estos procesos como elementos de y ampliación de la democracia.

Idealmente, la relación entre la revocatoria del mandato y la democracia puede verse a través de un doble prisma: por un lado, el hecho de que una revocatoria tenga lugar sería un indicio del buen funcionamiento de la democracia. Esto ocurriría porque -cumplidos los requisitos legales- las autoridades no quieren o no pueden activar mecanismos ad hoc para evitar un proceso en su contra, demostrando la fortaleza de un andamiaje institucional que permite el uso de un mecanismo directo de control ciudadano. Por otro lado, en contextos de crisis y polarización, la revocatoria podría aportar una solución institucional al conflicto, garantizando la supervivencia de la democracia y evitando el deterioro de las reglas del juego político. Es decir, la revocatoria podría funcionar a consecuencia del buen desempeño de la democracia y, a la vez, podría operar como un mecanismo capaz de fortalecerla, o al menos preservarla en contextos de crisis. Es de suponer que esta era la 
expectativa de los constituyentes al regular el mecanismo. Pero las normas no necesariamente crean instituciones.

Las instituciones son reglas con fuerza prescriptiva sobre los actores, lo que supone que son entendidas, avaladas y aceptadas por quienes están sujetos a las mismas (Ostrom, 1986). O’Donnell (1996) indica que las instituciones determinan qué agentes -sobre la base de qué recursos y procedimientos- se aceptan como participantes válidos en los procesos de toma de decisiones. A su vez, estos criterios se adecúan a unos actores y obligan a otros a redefinirse. Las instituciones también sugieren una probable distribución de resultados y excluyen otros, por ejemplo, las instituciones democráticas excluyen el uso de la fuerza. También tienen efectos sobre el nivel de acción y organización de los agentes que interactúan con ellas. En este sentido, un dispositivo de participación con un diseño modélico pero que nunca es utilizado no tiene ninguna consecuencia ${ }^{1}$, pero también puede ocurrir que las expectativas puestas por los legisladores al diseñar un mecanismo se materialicen en prácticas inesperadas, incluso opuestas a los objetivos iniciales.

Este trabajo se centra en las experiencias recientes de revocatoria del mandato en Lima y Bogotá, a fin de analizar la medida en que estos procesos han contribuido al fortalecimiento de la democracia. El texto se estructura en: (i) presentación de una revisión de los estudios sobre el tema con base a la que definimos nuestra propuesta analítica, luego (ii) un análisis de los casos y, finalmente, (iii) las conclusiones.

\section{Ciudadanía y poder}

Existe acuerdo en considerar que los MDD susceptibles de ser activados "desde abajo", mediante la recolección de firmas y el cumplimiento de otros requisitos, permiten que la ciudadanía siga siendo un actor de

1 Aún así, cabe considerar que una norma puede permanecer ignorada hasta que en un momento es incorporada al juego político. Por ejemplo, en Uruguay la iniciativa popular (para la reforma de la constitución) y el referéndum opcional legislativo (para la derogación de leyes) fueron introducidos constitucionalmente en 1967 , pero las primeras prácticas se registraron a fines de los ochenta. 
veto en el juego político (ver Tsebelis, 1995) así como un actor innovador, capaz de proponer y decidir políticas, ya que estos dispositivos abren la posibilidad de bloquear leyes (referéndum opcional), rechazarlas (referéndum derogatorio), proponerlas o modificarlas (iniciativa legislativa o constitucional), o bien revocar el mandato de representantes (referéndum revocatorio).

Estos mecanismos permiten fortalecer la accountability y, por ende, podrían conducir a reducir la distancia entre las acciones de los gobernantes y las preferencias de la ciudadanía. Pero sus potencialidades también podrían ser identificadas con razones por las que no es de esperar que tengan una amplia difusión: ¿qué podría llevar a actores con poder para tomar decisiones a compartir ese poder? En el análisis de la revocatoria la cuestión se vuelve más flagrante, porque los responsables de introducir el dispositivo podrían ser los principales afectados por el mismo.

Los estudios sobre la promoción de mecanismos de democracia directa desde abajo sugieren dos variables que podrían explicar su introducción: (i) contextos de crisis en que existe una extendida percepción de que los gobiernos son ineficientes y/o corruptos y (ii) surgimiento de movimientos sociales y políticos que promueven la participación ciudadana como componente fundamental de su propuesta ideológica ${ }^{2}$. Si la primera condición genera el terreno propicio, la segunda catapulta las demandas de cambio institucional.

La discusión sobre la viabilidad de los mecanismos de participación ciudadana enfrenta una visión elitista de la democracia (en la que predomina el miedo a la "tiranía de las mayorías" y a la supuesta incapacidad del ciudadano corriente para tomar decisiones vinculadas al interés general (Schumpeter, 1961) ${ }^{3}$ con otra mirada que asocia la participación

2 Estas ideas derivan de la literatura sobre la introducción de mecanismos de democracia directa a nivel subnacional en Estados Unidos (Spivak, 2004; Garret, 2004), algunos estudios sobre la democracia participativa en América Latina (Goldfrank, 2002; Schneider y Welp, 2011) y también en Suiza (Auer, 2009; Dardanelli, 2011; Serdült, 2014).

3 Cronin (1989) y Bowler et al. (1998) describen este aspecto en la discusión sobre la introducción de MDD a nivel federal en Estados Unidos (rechazada por los legisladores). 
ciudadana a sistemas políticos más legítimos y evolucionados (Almond y Verba, 1963; Pateman, 1970). A este debate sobre el rol político del ciudadano por fuera de los períodos de elección de autoridades, en las últimas décadas se ha sumado la discusión sobre la crisis de la democracia representativa. La misma es observada en la pérdida de afiliados de partidos políticos y sindicatos y en la creciente desconfianza de los ciudadanos en estas instituciones. La introducción de mecanismos de participación ciudadana sería una respuesta en el intento de superar o contrarrestar esta crisis (Dalton et al., 2001; Setälä, 1999).

La introducción de MDD fue resultado de una lucha por evitar la excesiva concentración de poder en manos de los gobernantes o de algunas unidades de gobierno durante procesos de centralización o descentralización. En los países en que se registra una más larga tradición -Suiza y Estados Unidos- la introducción de MDD se remonta a la fundación del Estado. Pero mientras Suiza aparece como el primer país moderno en introducir dispositivos de participación ciudadana directa en todos los niveles de gobierno (Auer, 2008), en Estados Unidos se introdujeron solo en el nivel subnacional (Spivak, 2004). En lo que refiere a la revocatoria, no está legislada a nivel federal en Suiza y en los pocos cantones que la contemplan ha caído en desuso (con la excepción de intentos recientes en Ticino ${ }^{4}$ ), mientras algunos autores han observado un crecimiento de intentos en el nivel subnacional estadounidense (Spivak, 2004).

En su análisis del caso suizo, Serdült (2014) señala que las pocas experiencias - una activación y unos pocos intentos en más de un siglo- sugieren que la revocatoria ha perdido peso, convirtiéndose en un mecanismo prácticamente inutilizado. Esto obedecería a: i) la consolidación y creciente importancia de otros mecanismos de democracia directa, que otorgan poder a los ciudadanos para intervenir en la definición de los asuntos públicos (en lugar de centrar esfuerzos en remover

4 En Ticino, los frecuentes conflictos y bloqueos interpartidarios han vuelto a colocar el mecanismo en la agenda. Los cantones en que existen provisiones para activar revocatorias son Berna, Uri, Solothurn, Schaffhausen, Thurgau y Ticino (Serdült 2014). 
autoridades); y ii) la vigencia de garantías institucionales, particularmente el buen funcionamiento de la justicia (que no hace necesario dirimir asuntos de corrupción por este medio). Por su parte, los análisis centrados en Estados Unidos la identifican con un mecanismo a activar cuando no existen o no funcionan bien otros contrapesos (sanciones administrativas, control judicial) o cuando son los mismos partidos quienes recurren a ella para enfrentar políticas que rechazan (Spivak, 2004; Qvordrup, 2014).

En los países andinos, la introducción de mecanismos de democracia directa $-y$ entre ellos la revocatoria- se produjo principalmente a partir de la década del noventa, por vía de la asamblea constituyente (Colombia 1991; Perú 1993; Ecuador 1998 y 2008; Venezuela 1999; Bolivia 2009) $)^{5}$. En estos casos, los estudios ponen énfasis en una serie de obstáculos que, o bien impedirían la utilización de la revocatoria, o bien evidenciarían que dicha activación no es producto de una "legítima" participación ciudadana sino de la manipulación política. Así, algunos señalan que las revocatorias son difíciles de activar por los elevados requisitos y por la apatía ciudadana (Breuer, 2010; Bustos, 2002) o por la falta de independencia de organismos electorales que ponen obstáculos a las activaciones (Jiménez, 2001; Welp, 2013; Arques, 2014). A su vez, cuando son activados, se observa que a menudo los promotores son los opositores en las sombras (Vásquez Oruna, 2014; Franco Cuervo, 2014). Pero la revocatoria cuenta también con defensores, que la identifican como un potente mecanismo de control capaz de fortalecer la democracia (Quintanilla, 2012). Explorar las condiciones en que uno u otro resultado producen es uno de los objetivos de este trabajo.

Nuestro análisis se centra en la suposición de que la revocatoria sería un resultado del buen funcionamiento institucional cuando se cumplen condiciones tales como las siguientes:

(a) la ciudadanía activa el mecanismo para enfrentar a una autoridad que ha perdido su legitimidad por causas asociadas a la gestión;

5 La revocatoria fue introducida previamente en Cuba y Argentina (Welp y Serdült, 2014). Por detalles de los procesos de introducción en los países andinos (véase Welp y Serdült 2011). 
(b) si se cumplen los requisitos, las instituciones competentes convocan la consulta y la misma tiene lugar garantizando los derechos de las partes y de la ciudadanía (tanto durante la campaña como durante el acto comicial).

Por el contrario, la revocatoria evidenciaría problemas de funcionamiento o consolidación de la democracia si fuera utilizada por otros actores (por ejemplo, los partidos políticos o los candidatos que perdieron en la elección previa) para resolver cuentas ajenas a la gestión de la autoridad cuestionada. Otro tanto ocurriría si la ciudadanía organizada encuentra obstáculos creados ad hoc para impedir la activación del mecanismo, pese a haber cumplido con los requisitos formales.

Por otra parte, el proceso culminaría con un fortalecimiento de la democracia si:

(d) la confianza en el sistema político se incrementa;

(e) el gobierno ratificado incrementa su confianza y capacidad de gestión, o si, de ser desplazado, se resuelve el conflicto por vías democráticas.

Por el contrario, el mecanismo se mostraría ineficiente si el conflicto persistiese, revocada o no la autoridad, y la ciudadanía no incrementase su confianza en el sistema.

\section{Análisis del caso peruano y colombiano}

Antes de abordar el análisis de los casos nos detendremos en algunos aspectos relacionados con la introducción, regulación y ejercicio de la revocatoria del mandato en Colombia y Perú.

En Colombia, la revocatoria fue incluida por la asamblea constituyente reunida en Bogotá en 1991, convocada como respuesta a un reclamo ciudadano expresado en el movimiento "la séptima papeleta", que pedía una reforma constitucional para terminar con la violencia, el narcoterrorismo, la corrupción y la creciente apatía ciudadana (baste a modo de ejemplo recordar que en la misma elección de la asamblea constituyente la abstención alcanzó el 75\%). Un referéndum informal, 
posteriormente avalado por las autoridades, pidió la reforma y la inclusión de mecanismos de democracia directa y participativa.

La discusión de la constituyente en torno al mecanismo incluyó referencias a la evolución democrática requerida para el ejercicio de instrumentos de participación ${ }^{6}$. El constituyente Antonio Galán Sarmiento propuso la revocatoria basada en el mandato programático: "Al residir la soberanía en el pueblo (...) este otorga un mandato a sus elegidos cuya claridad dependerá de haber hecho explícitas antes de las elecciones un programa por parte del mandatario, el cual se compromete a defender y por cuyo incumplimiento sus electores pueden llamarlo a cuentas y revocarle el mandato" (Gaceta Constitucional 081/1991: 8-9).

Lejos del contexto de presión ciudadana, en Perú, el proceso constituyente de 1993 fue iniciado como una salida de emergencia ideada por Alberto Fujimori tras el "autogolpe" que clausuró el congreso. El rechazo internacional a la ruptura de la legalidad, y en particular el rol de la Organización de Estados Americanos (OEA) presionando por la restauración de la institucionalidad, condujo a un acuerdo por el que Fujimori se comprometía a convocar elecciones para formar una asamblea constituyente. Los mecanismos de democracia directa fueron introducidos junto a otras reformas controvertidas, como la eliminación de una de las cámaras del parlamento o la introducción de la pena de muerte (Levitsky, 1999).

Además, el mecanismo se propuso como contrapartida de la ampliación de mandatos de los alcaldes de tres a cinco años; se introdujo en tanto derecho político, con lo que su activación requiere de fundamentación pero no de pruebas.

En ambos casos la revocatoria puede activarse solo contra autoridades subnacionales (frente a lo que ocurre en Ecuador, Bolivia y Vene-

6 El análisis comparado presentado durante la constituyente llevó a concluir que "la revocatoria del mandato es una figura con muy poco desarrollo; puesto que su existencia exige una cultura política avanzada, no solo en el electorado sino en los partidos, movimientos y grupos políticos. Lo anterior, permite afirmar que en este sentido se está desarrollando aún la democracia y por ello no podemos ni trasladar, ni copiar las fórmulas adoptadas en otros países" (Gaceta Constitucional 066/1991: 97). 
zuela, en que todas las autoridades electas pueden ser revocadas, incluso el presidente) (Welp y Serdült, 2011). Sin embargo, en Colombia el mecanismo se refiere solo a las autoridades ejecutivas (alcaldes y gobernadores) mientras en Perú también los legisladores pueden ser revocados (ver más detalles en la próxima sección). El análisis de las prácticas muestra profundas diferencias en una cuestión básica: la frecuencia de uso. En Colombia, desde que se reguló el mecanismo con la Ley 134 de 1994 hasta 2013, apenas treinta y seis iniciativas terminaron en referendo y ninguna prosperó por no alcanzar el umbral de participación requerido. En Perú, las autoridades sometidas a procesos revocatorios han sido más de cinco mil en menos de dos décadas (desde 1997) ${ }^{7}$. Estos apuntes dan marco al análisis de los casos, que se presenta a continuación.

\section{Lima}

Susana Villarán (Fuerza Social) alcanzó la alcaldía de Lima tras triunfar sorpresivamente en las elecciones del 3 de octubre de 2010. En agosto de ese ańo la candidatura de Villarán apenas contaba con el 6 por ciento de apoyo; sin embargo, cuando el Juzgado Nacional de Elecciones (JNE) inhabilitó a uno de los dos favoritos, Alex Kuori Buchamar, la líder de Fuerza Social se convirtió en la competidora de Lourdes Flores Nano, del Partido Popular Cristiano (PPC). Acusada de ser una representante de la extrema izquierda, Villarán enfrentó la oposición de los principales medios de comunicación. Su candidatura contó con el apoyo de fuerzas progresistas. Inició un gobierno débil, triunfando por un escaso $0,83 \%{ }^{8}$. Pese a que la ley electoral garantiza la mayoría absoluta en el concejo, su partido no ganó ninguno de los 42 distritos de Lima Metropolitana.

Una vez en la alcaldía, Villarán tomó una serie de decisiones que le granjearon numerosos enemigos. A escasos cien días de iniciada su

7 Por un análisis detallado véase Welp, 2013.

8 http://portal.jne.gob.pe/informacionelectoral/estadisticaelectoral/COMPENDIO_ESTADISTICO.pdf 
gestión, presentó los resultados de una auditoría que denunciaba el mal uso de fondos públicos por parte del alcalde anterior, Luis Castañeda, decidió regular el sistema de transporte local, controlado por mafias; y más tarde, apoyó al movimiento LGTB (lesbianas, gays, transexuales y bisexuales) en un país con una fuerte influencia de las ramas más conservadoras de la iglesia católica ${ }^{9}$. En ese contexto, no fue extraño que la revocatoria entrara en escena muy rápidamente.

En Perú, la revocatoria puede activarse entre el segundo y el tercer ańo de gestión, la solicitud debe ser fundamentada pero no probada. El referendo es individual, pero si se revoca a más de un tercio de las autoridades del concejo, la ley obliga a convocar nuevas elecciones para reemplazar (solo) a los que han sido revocados. Esto promueve los "incentivos perversos" de los que habla Tuesta Soldevilla (2014) al analizar el caso peruano, los cuales generan condiciones para que líderes políticos intenten activar revocatorias a fin de alcanzar el poder, en escenarios de baja institucionalización de los partidos y elevada fragmentación y volatilidad. La ley fija en un 25\% el umbral de firmas requeridos para activar una revocatoria, pero el número absoluto no puede superar las 400000 , lo que ubica a Lima en una situación especial: en 2011, menos del 7\% de firmas del padrón bastaban para activar una revocatoria. Además, no hay un plazo para reunir firmas ${ }^{10}$, lo que permite a los promotores sacar provecho de cualquier incidente que ocurra durante el proceso.

La solicitud de revocatoria fue presentada por Marco Tulio Gutiérrez, un antiguo regidor de Izquierda Unida (1980-1983) que había trabajado con Luis Castañeda. La revocatoria fue apoyada desde sus inicios por los transportistas, los comerciantes ambulantes del centro de Lima, los pequeños empresarios de imprentas, los pobladores de la margen izquierda del río Rímac, las organizaciones de personas dis-

9 Vasquez Oruna (2014) destaca también el peso que habría tenido el cambio en el estilo de gobierno en lo que refiere a publicitar obras. A diferencia de lo que habría ocurrido en la gestión anterior, Villarán sostenía que "Los recursos son del pueblo y yo no tengo por qué poner mi nombre en los carteles de obras que se hacen con los recursos del pueblo" Diario La Primera. Las obras de Villarán, 8 de julio de 2011.

10 A diferencia de otros casos sudamericanos: en Bolivia 90 días o en Colombia 180 días. 
capacitadas y algunas ex autoridades de Lima. Sectores conservadores asociados a la iglesia también se adhirieron (Vasquez Oruna, 2014).

En julio de 2012 los promotores presentaron 400396 firmas para revocar a la alcaldesa y todo el concejo ( 40 miembros), mostrando la intención de convocar a nuevas elecciones. La validación de las firmas abrió un proceso largo y muy discutido por los promotores y las tres instituciones a cargo de un proceso electoral en el Perú (RENIEC, ONPE y el JNE). Finalmente la JNE convocó la consulta para el 17 de marzo de 2013, "por ineficiencia de desempeño de sus funciones".

La posición tomada por los partidos políticos otorga validez a la idea de que la fragmentación y baja institucionalización de los partidos explica la constante activación de revocatorias en los pequeńos distritos peruanos, en que la volatilidad no otorga garantías de supervivencia y alimenta el juego antisistema (mientras partidos con expectativas de supervivencia serían reacios a iniciar lo que podría convertirse en un proceso sin fin de revocatorias). La revocatoria fue apoyada también por el Partido Aprista y el evangélico Restauración Nacional. Solidaridad Nacional, de Luis Castańeda, también dio su apoyo, pero solo pocos días antes de la consulta. El conservador PPC encabezado por Lourdes Flores (derrotada por Villarán en las elecciones) apoyó el "no" a la revocatoria y defendió las elecciones regulares como mecanismo de rendición de cuentas. El fujimorismo, encabezado por Keiko Fujimori, dio libertad de opinión a sus votantes. El partido de Ollanta Humala no se pronunció oficialmente pese a que varios dirigentes se manifestaron a favor del "no". También se mostraron a favor del "no", Acción Popular, Somos Perú, Perú Posible, Alianza por el Progreso, el Partido Nacionalista (La República, 13/12/2012).

Dado que en Perú la revocatoria es un proceso individual, se requería un voto por cada miembro del concejo. El resultado final fue la validación de la alcaldesa en su cargo ${ }^{11}$, pero la destitución de la

11 Entre otras razones, la difusión de un audio mostrando que el ex alcalde Castañeda Losio (denunciada por Villarán por mala gestión y mal uso de fondos públicos) estaba detrás del intento pese a haberlo negado convenció a muchos electores de apoyar a la alcaldesa. 
mayoría de los miembros del concejo le ha llevado a perder la mayoría absoluta al convocarse nuevas elecciones y dirimirse las mismas por el sistema proporcional (contrario a lo que ocurre en la elección regular, que garantiza mayoría absoluta al acalde/sa). Además de la crisis de gobernabilidad que la situación parece conllevar, no parece haber resuelto el impasse entre los diferentes actores, ya que quienes querían revocar a la alcaldesa han continuado sus demandas, iniciando un proceso para su remoción por ineficiencia y mala gestión (la alternativa que se concretó en Bogotá).

\section{Bogotá}

Gustavo Francisco Petro Urrego llegó a la alcaldía de Bogotá por el movimiento Progresistas, tras obtener el 32,2\% de los votos en unos comicios que contaron con la participación del 47,4\% del padrón electoral. Fue seguido por el candidato de la alianza entre el Partido Verde - Partido Social de Unidad Nacional, Enrique Peńalosa, que obtuvo el 24,98\% de los votos. Gina Parody (independiente) quedó en tercer lugar con el 16,76\% de los votos ${ }^{12}$.

La gestión de Petro comenzó el 1 de enero de 2012. Para diciembre de ese año ya enfrentaba la apertura de una investigación por la Procuraduría General de la Nación, que decidió investigar presuntas irregularidades en la definición del nuevo sistema de aseo y recolección de basuras, y las contrataciones vinculadas al mismo. El hecho se inscribe en una larga lista de funcionarios investigados, sancionados y destituidos por el actual Procurador de la Nación, Alejandro Ordoñez (que entre 2009 y 2013 ordenó la destitución de 49 gobernadores y ex gobernadores, 828 alcaldes y ex alcaldes), representante de la derecha colombiana (Franco Cuervo, 2014).

Casi al mismo tiempo se le abría a Petro otro frente de batalla, con la solicitud de revocatoria radicada por Miguel Gómez Martínez (legis-

12 Fuente: http://w3.registraduria.gov.co/escrutinio/resultados 
lador por Bogotá, representante del Partido de la U) en enero de 2013. Entre los argumentos se encontraba el deterioro de la movilidad de la ciudad, el sistema de recolección de basura y la salud de los ciudadanos (El Tiempo, 2/01/2013).

En Colombia los únicos cargos electivos que pueden ser revocados son los de alcaldes y gobernadores. Las razones que fundamentan una solicitud son la insatisfacción general de la ciudadanía o el incumplimiento del programa de gobierno; y la misma puede ser presentada transcurrido no menos de un ańo de ejercicio del cargo, ante la Registraduría del distrito (artículo 65). De acuerdo con la Ley 131 de 1994 para convocar el referéndum se requiere la adhesión del $40 \%$ de los votos válidos registrados en la elección del mandatario a revocar. Para que los comicios sean válidos el umbral de participación no puede ser inferior al 55\% de la votación registrada el día que el mandatario resultó electo. Este requisito es resultado de las reformas introducidas con la Ley 741 de $2002^{13}$. Para que la autoridad sea revocada, la opción debe conseguir el apoyo de la mitad más uno de los electores.

Luego de haber validado las firmas presentadas por el promotor - se requería un mínimo de 289263 firmas: en el mes de junio la Registraduría Distrital dio curso al proceso de revocatoria. La defensa de Petro presentó un recurso de apelación y consiguió que se pospusiera la convocatoria a elecciones - prevista para noviembre de 2013-, fijándose la fecha de la consulta popular para el 2 de marzo de 2014, en la que debían participar 1234214 bogotanos para que fuera válida. Finalmente, en diciembre de 2013, la Procuraduría emitió un fallo destituyendo al alcalde e inhabilitándolo por quince años para ejercer cargos públicos (Resolución 340/2014), una condena que se consideró excesiva mien-

13 Las modificaciones de la Ley 134/94, tendientes a disminuir los obstáculos formales, generaron un sensible aumento en la presentación de revocatorias a partir de 2003 (Franco Cuervo, 2014), pese a que el país sigue presentando una escasa tradición en el empleo del mecanismo si se lo compara con otros casos (Welp, 2013), y en todas las ocasiones en que las solicitudes han llegado a las urnas, las autoridades sometidas a consulta fueron ratificadas en su cargo debido a la elevada abstención que invalida los comicios. 
tras puso en discusión las competencias de la institución ${ }^{14}$. Entonces, el equipo de Petro presentó un recurso ante la Corte Interamericana de Derechos Humanos (CIDH), que mediante Resolución 5/2014, solicitó al Estado colombiano suspender los efectos de la decisión de la Procuraduría. En principio el presidente Santos desconoció el fallo, pero finalmente Petro fue restituido en su cargo el 23 de abril de 2014.

El intento revocatorio se convirtió en una cuestión de alcance nacional, y hasta regional ${ }^{15}$, mientras se cuestionó el rol de la Procuraduría para destituir autoridades electas por voto popular, y en particular, se criticaron las medidas del actual procurador, acusado de impartir sanciones de acuerdo con criterios políticos (La Semana, 22/06/2013). En un primer momento, el alcalde se mostró favorable a la concurrencia de los bogotanos a las urnas, en pos del fortalecimiento democrático y como forma de (re) legitimar su gestión frente a una opinión pública crecientemente desfavorable. Según una encuesta de Ipsos-Napoleón Franco de abril de 2013, el descontento con la gestión de Petro alcanzaba el $61 \%$ de los encuestados, frente a un $28 \%$ favorable. No obstante, una vez que la revocatoria fue inminente, Petro complementó la estrategia de movilización de apoyos con el recurso a tutelas judiciales para dilatar el proceso e intentar deslegitimar la revocatoria. Pero cuando la destitución se convirtió en un problema más apremiante para el alcalde, la cuestión de la revocatoria se transformó en una herramienta del discurso petrista para apelar a la voluntad popular en lugar de a la decisión de una institución "no legitimada" por el electorado (Rey, 2014).

14 Según el artículo 278 de la Constitución colombiana, entre las funciones del Procurador General de la Nación se encuentra la de "1. Desvincular del cargo, previa audiencia y mediante decisión motivada, al funcionario público que incurra en alguna de las siguientes faltas: infringir de manera manifiesta la Constitución o la ley; derivar evidente e indebido provecho patrimonial en el ejercicio de su cargo o de sus funciones; obstaculizar, en forma grave, las investigaciones que realice la Procuraduría o una autoridad administrativa o jurisdiccional; obrar con manifiesta negligencia en la investigación y sanción de las faltas disciplinarias de los empleados de su dependencia, o en la denuncia de los hechos punibles de que tenga conocimiento en razón del ejercicio de su cargo."

15 Incluso la Red de Ciudades Suramericanas expresó su preocupación por la destitución de Petro a través de una carta firmada por alcaldes de distintas ciudades de la región tales como Augusto Barrera (alcalde de Quito), Mauricio Macri (Buenos Aires) y Susana Villarán (alcaldesa de Lima, quien también sufrió un intento de revocatoria) (Noticias Quito, 12/11/2013) 
Los petristas impulsaron la "campaña por el no" valiéndose principalmente de las redes sociales - acusando a los principales medios de comunicación de encontrarse bajo monopolio del estado nacional- y convocando con éxito a multitudinarias manifestaciones y actos públicos en la Plaza Bolívar de Bogotá. Se constituyó con este fin el llamado "Comité de Defensa de la Bogotá Humana”, compuesto por más de 30 "nodos" que agrupaban distintos colectivos (animalistas, movimiento LGTB, partidos políticos y agrupaciones de izquierda, indígenas, ex miembros del M19, sindicatos, recicladores, entre otros). Los resultados fueron evidentes en la creciente popularidad de Petro, que de acuerdo a las encuestas alcanzó un 62\%; en un movimiento que parecería indicar el rechazo a la decisión del procurador de destituirlo del cargo (La Silla Vacía, 09/02/2014).

\section{Conclusiones}

Concluido el análisis de los casos, la primera pregunta a la que estas conclusiones buscan dar una respuesta refiere a la existencia o no de una base ciudadana de las revocatorias, en otras palabras, a su legitimidad. Esto lleva a considerar, entre otras, la cuestión de los promotores de los procesos revocatorios, así como el quórum otorgado por la ciudadanía posteriormente para avalar y luego validar una revocatoria. Los análisis presentados muestran una imagen compleja. Más allá de la consideración sobre lo elevado o reducido del número de firmas requeridas para activar una revocatoria, en ambos casos las evidencias sugieren que las firmas se reunieron. Por otra parte, sucesivas encuestas señalan que existía un descontento con ambas gestiones. Ahora bien, ¿es ese descontento una particularidad de estos casos (de la gestión de Villarán y de Petro) o un hecho que atraviesa largamente la gestión de las grandes ciudades latinoamericanas, asoladas por numerosos problemas y con recursos insuficientes para afrontarlos? Vásquez Oruna (2014: 51) aborda esta cuestión en su estudio de Lima y llega a la conclusión de que el gobierno de Villarán no destacaba entre los gobiernos previos, 
encontrándose en la media. La alta abstención electoral y las numerosas crisis vividas en Bogotá en particular, y Colombia en general, parecen sugerir un escenario semejante. Es en este contexto que el desencanto ciudadano confluye con los intereses de líderes políticos que de forma abierta o encubierta optan por manipular las reglas a su favor.

En Lima, cumplidos los requisitos de activación, el proceso tuvo lugar. Aunque hubo enfrentamientos y polémicas (firmas falsas, entre muchas otras irregularidades), la actitud de Villarán, coherente en su respeto al cumplimiento de las reglas del juego, parece haber contribuido a mantener la confianza en el proceso electoral. Por el contrario, las irregularidades observadas en el caso colombiano, la cuestionada intervención de la Procuraduría y la misma actitud errática de Petro (primero a favor, luego en contra y finalmente a favor de que se convoque la revocatoria), dan señales de la debilidad del andamiaje institucional.

Finalmente, y a pesar de las diferencias entre ambos procesos, ninguno parece haber contribuido al fortalecimiento de la democracia. En Lima esto se debe a que, si bien Villarán fue ratificada, perdió su mayoría absoluta y su gobierno vivió transformaciones que afectaron profundamente a la gobernabilidad (en los cuatro ańos funcionó el gobierno electo, luego asumieron las autoridades provisionales y finalmente las electas en las nuevas elecciones) mientras la oposición tampoco aceptó los resultados como legítimos y continuó con sus intentos de remover a la alcaldesa. En Bogotá, la cancelación de la revocatoria ha puesto en evidencia las debilidades de la democracia colombiana, que refieren tanto a los diseños institucionales (poder excesivo otorgado a la Procuraduría), como al escaso apego a las reglas del juego manifestado por los distintos actores. 


\section{Bibliografía}

Almond, G. y Verba, S. (1963). The Civic Culture. Sage Publications Arques, F. (2014). "Argentina: una herramienta de los gobernados en manos de los gobernantes", en La dosis hace el veneno. La revocatoria del mandato en América Latina, Estados Unidos y Suiza. Welp y Serüldt (Coords.), Ecuador: Instituto de la Democracia.

Auer, A. (2008) "Una mirada suiza sobre la democracia directa en América Latina", en Democracia Directa en Latinoamerica. Lissidini, Welp y Zovatto (Coords.), Buenos Aires: Prometeo.

Bowler, S.; Donovan, T. y Tolbert, C. (1998). Citizens as legislators: direct democracy in the United States. Columbus: Ohio State University Press.

Breuer, A. (2010) "Investigando la baja frecuencia de uso de mecanismos de democracia directa de iniciativa ciudadana en América Latina: Lecciones del caso colombiano", paper presentado en el Annual Congress of the Latin American Studies Association (LASA), 6-9 de octubre, Toronto, Canada.

Bustos, C. (2002) "Los mecanismos de participación democrática: ficción o realidad", en Revista Facultad de Ciencias Económicas: Investigación y Reflexión, nº01: 68-77.

Jimenez, W. (2001) "Revocatoria del mandato: experiencias, dificultades, ajustes necesarios", en Territorios no5: 35-48.

Cronin, T. (1989). “The Recall Device”, en Direct Democracy. The Politics of Referendum, Initiative and Recall. Harvard University Press.

Franco Cuervo, A. (2014) "La revocatoria del mandato en Colombia" en La dosis hace el veneno. La revocatoria del mandato en América Latina, Estados Unidos y Suiza. Welp y Serüldt (Coords.), Ecuador: Instituto de la Democracia.

Dalton, R.; Bürklin, Wilhelm y Drummond, A. (2001) "Public Opinion and Direct Democracy", en Journal of Democracy, vol. 12: 141-153. 
Dardanelli, P. (2011). "The emergence and evolution of democracy in Switzerland", en de MALONE, M. F., Achieving democracy. Democratization in theory and practice. Londres: Ed. Continuum.

Garrett, E. (2004). "Democracy in the Wake of the California Recall," U. Pa. L. Rev., vol 153: 239.

Goldfrank, B. (2002). “The Fragile Flower of Local Democracy: A Case Study of Decentralization/Participation in Montevideo", en Politics $\&$ Society.

Levitsky, S. (1999). "Fujimori and Post-Party Politics in Peru", Journal of Democracy, Vol. 10, No 3: 78-92.

O’Donnell, G. (1996) “Otra institucionalización”, en Ágora, vol 5: 5-28.

Ostrom, E. (1986) "An agenda for the study of institutions", en Public Choice.

Pateman, C. (1970). Participation and Democratic Theory, Cambridge, Cambridge University Press.

Quintanilla, A. (2013). "El debate sobre la revocatoria y las reformas de la ley 26300", en "Perú Hoy. Susurros desde Babel” Ed Desco.

Qvardrup, M. (2014). "La experiencia estadounidense de 1776 a 2012”, en La dosis hace el veneno. La revocatoria del mandato en Suiza, Estados Unidos y América Latina. WELP y SERÜLDT (Coords.), Ecuador: Instituto de la Democracia, CNE-TCE.

Rey, J. (2014) "Entre la revocatoria y la destitución. Análisis de la frustrada experiencia de revocar al alcalde de Bogotá Gustavo petro", c2d Working Papers.

Schneider, C. y Welp, Y. (2011). "Orígenes y contradicciones de la participación ciudadana institucional. Análisis de las experiencias de Buenos Aires, Montevideo, Barcelona y Zurich", en Revista Mexicana de Ciencias Politicas y Sociales No. 212 (mayo-agosto)

Schumpeter, J. (1961). "Capitalismo, Socialismo y Democracia”, Madrid: Alianza. 
Serdült, U. (2014) "Una institución durmiente: la revocatoria en Suiza”, Welp y Serdült (eds.) La dosis hace el veneno. La revocatoria del mandato en Suiza, Estados Unidos y América Latina.

Serdült, U. y Welp, Y. (2012) “Direct Democracy Upside Down”, en Taiwan Journal of Democracy, 8 (1)

Setälä, M. (1999). "Referendums in Western Europe - A Wave of Direct Democracy”, en Scandinavian Political Studies, vol. 22: pp. 327-340.

Spivak, J. (2004) "Califoria’s Recall. Adoption of the 'Grand Bounce' for Elected Officials", en California History, vol 81, n²2.

Tsebelis, G. (1995). "Decision making in political systems: veto players in presidentialism, parliamentarism, multicameralism and multipartysism", en British Journal of Political Science, vol. 25, no 3: pp. 289-325.

Tuesta Soldevilla, F. (2014). "Perú: Entre la participación y la gobernabilidad local", en La dosis hace el veneno. La revocatoria del mandato en América Latina, Estados Unidos y Suiza. Welp y Serüldt (Coords.), Ecuador: Instituto de la Democracia.

Vásquez Oruna, M. (2014). "Cuando los vientos revocadores azotaron Lima”, en La dosis hace el veneno. La revocatoria del mandato en América Latina, Estados Unidos y Suiza. Welp y Serüldt (Coords.), Ecuador: Instituto de la Democracia.

Welp, Y. y Serüldt, U. (Coords.) (2014). La dosis hace el veneno. La revocatoria del mandato en América Latina, Estados Unidos y Suiza. Ecuador: Instituto de la Democracia.

Welp, Y. (2013). “¡Por qué Perú? Análisis de la revocatoria del mandato en perspectiva comparada. Elecciones 12 (13).

Welp, Y. y Serdült, U. (2011). “JJaque a la representación? Análisis de la revocatoria de mandato en los gobiernos locales de América Latina”, en Welp y Whitehead, Caleidoscopio de la innovación democrática en América Latina, México: FLACSO. 
Artículos en medios

El Tiempo (2/01/2013) “Oficializan campaña para revocar mandato de alcalde Petro" http://www.eltiempo.com/archivo/documento/ CMS-12488201

Noticias Quito, 12/11/2013 "Alcaldes de Sudamérica rechazan destitución de Gustavo Petro" Link: http://www.noticiasquito.gob.ec/ Noticias/news_user_view/alcaldes_de_sudamerica_rechazan_destitucion_de_gustavo_petro--10440

La Semana (22/06/2013) "El alcalde Gustavo Petro está en la mira" http://www.semana.com/nacion/articulo/el-alcalde-gustavo-petro-esta-mira/348462-3

La República (13/12/2012) "Partidos políticos empiezan a participar con fuerza en campaña por el No" . Link: http://www.larepublica. pe/13-02-2013/partidos-politicos-empiezan-participar-con-fuerza-en-campana-por-el-no

La Silla Vacía (09/02/2014) “Así es la campaña por el no”. Link: http:// lasillavacia.com/historia/sin-candidatos-y-montada-en-la-popularidad-de-petro-asi-es-la-campana-por-el-no-46606

Normativa y documentos oficiales

Gaceta Constitucional de la Asamblea Constituyente 081 (1991) Bogotá. 